\title{
Laparoscopic ovarian drilling (LOD) in patients with polycystic ovary syndrome (PCOS): an alternative approach to medical treatment?
}

Received: 21 October 2004 / Accepted: 14 March 2005 / Published online: 13 May 2005

(C) Springer-Verlag Berlin / Heidelberg 2005

\begin{abstract}
The operative treatment of polycystic ovary syndrome (PCOS) patients by laparoscopic ovarian drilling (LOD) is a widely used technique. However, the indication remains unclear. Excellent results with ovulatory cycles up to 9 years after surgery have been described. Nevertheless, pregnancy rates are not superior to a course of three to six treatment cycles with gonadotrophins in low-dose protocols.
\end{abstract}

Keywords PCOS $\cdot$ Infertility $\cdot$ Ovarian drilling

\section{Introduction}

Polycystic ovary syndrome (PCOS) is a common endocrine disorder in up to $10 \%$ of women in the reproductive age. It comprises a heterogenous mixture of clinical and diagnostical findings, including oligo-/amenorrhoea, oligo-/anovulation, hirsutism, hyperandrogenaemia, a typical ovarian morphology and insulin resistance. Diagnostic criteria were defined by the ESHRE-ASRM consensus meeting in Rotterdam 2003 [1]. The main criteria are oligo- or anovulation, clinical and/ or biochemical signs of hyperandrogenism and polycystic ovaries by ultrasound. At least two out of these three criteria must be present. Furthermore, other aetiological factors, like M. Cushing, androgen-producing tumours or congenital adrenal hyperplasia must be excluded.

The aetiology of the PCOS is based on two major concepts; hyperandrogenism and insulin resistency. The classical hypothesis as proposed by Yen [2] postulates an

\footnotetext{
T. Strowitzki $(\varangle) \cdot$ M. von Wolff

Dept. of Gynecological Endocrinology and Reproductive

Medicine, University of Heidelberg, Vossstrasse 9,

69115 Heidelberg, Germany

E-mail: thomas_strowitzki@med.uni-heidelberg.de

Tel.: + 49-6221-567910

Fax: + 49-6221-564099
}

initial androgen excess. Androgens are aromatised in peripheral tissue to oestrogens, resulting in an imbalance of luteinizing hormone ( $\mathrm{LH})$ and follicle stimulating hormone (FSH) secretion on the pituitary level with endogenous hypersecretion of LH. The LH strongly stimulates the intraovarian androgen production. This classical concept has been extended by the role of hyperinsulinaemia in PCOS patients. Insulin resistance can be found in up to $50 \%$ of women with PCOS [3]. Insulin, like LH, stimulates directly the ovarian biosynthesis of steroid hormones, in particular, of ovarian androgens. Furthermore, insulin decreases the sex-hormone-binding globulin (SHBG) production in the liver, thus, further elevating free androgen levels [4-8]. Therefore, both pathways end in the stimulation of ovarian theca cells with elevated ovarian androgen production, resulting in disturbed folliculogenesis, cycle disorders and chronic oligo-/anovulation. This pivotal role of the ovary for the aetiology of the PCOS has favoured therapeutical concepts, which might directly correct the intraovarian pathology.

Besides these leading concepts, PCOS might be caused by enzymatic defects of steroidogenesis, for example, an increased activity of $5 \alpha$-reductase [9], an increased adrenal corticoid secretion or a dysregulation of the ovarian cytochrome-P450C17 $\alpha$-enzyme complex [10].

Current therapeutic concepts are mainly based on correction of the hyperinsulinemic state, direct ovarian stimulation or treatment of hyperandrogenemia by oral contraceptives with antiandrogenic gestagen components.

Similar to metformin treatment, operative procedures aim to restore spontaneous ovulatory cycles. The first invasive approach to treat polycystic ovaries was performed by ovarian wedge resection, described as early as 1935 by Stein and Cohen [11]. Although followed by severe de novo adhesion formation, this technique has been used successfully in many studies [12-14]. In a series of 173 wedge resections, Buttram and Vaquero were able to perform a second-look laparoscopy or laparotomy in 34 patients. None of these patients 
showed ovaries free of adhesions [13]. Lunde et al. [15] examined 149 patients $10-15$ years after previous wedge resection. Kaplan-Meier evaluation revealed a cumulative pregnancy rate of $76 \%(69.5 \%$ patients suffered from postoperative adhesions, counting for an infertility rate of $13.4 \%$ ). However, most of the patients still reported regular menstrual cycles after a period of up to 25 years.

\section{Technique of laparoscopic ovarian drilling}

The laparoscopic approach to ovarian drilling as a substitute of open surgical wedge resection was firstly described by Gjönnaess in 1984 [16]. The technique is based on drilling an undefined number of holes into the ovarian surface. Some studies have described a number of up to 40 holes for each ovary. Different instruments have been used so far, for example, monopolar diathermy, bipolar electrocauterisation, simple incision and various laser systems: $\mathrm{CO}_{2}$ [17], argon [17] or Nd:YAG [18]. The different techniques are summarised in Table 1.

\section{Electrocauterisation}

The initial technique described by Gjönnaess [16] used a unipolar biopsy or sterilisation forceps. Penetration of the ovarian capsule was reached by pressing the electrode on the ovarian surface for 2-4 s, using a power of 200-300 W. Each hole had an average diameter of $3 \mathrm{~mm}$ and a depth of $2-4 \mathrm{~mm}$. Three to eight holes were created in each ovary. In most studies, a three-puncture technique was used [26, 46, 30]. Liguori et al. [30] described the same size of drilled holes by unipolar electrocautery, but a higher number of 5-20 sites per ovary. Amer et al. [38] used a specially designed diathermy probe with a distal stainless steel needle measuring $8 \mathrm{~mm}$ in length and $2 \mathrm{~mm}$ in diameter, projecting from an insulated solid cone of $6 \mathrm{~mm}$ maximum diameter. Monopolar coagulation was reached with $30 \mathrm{~W}$ power and 3-10 punctures were made in each ovary, each measuring $4 \mathrm{~mm}$ in diameter and $5-7 \mathrm{~mm}$ in depth.

A bipolar insulated needle has been described as well [43]. In this study, each ovary was punctured 5-10 times, depending on its size.

\section{Laser techniques}

The $\mathrm{CO}_{2}$ laser technique reduces the number of subcapsular small follicles and should destroy androgenproducing tissue. Usually, a power of $10-20 \mathrm{~W}$ in continuous mode is used with a power density of up to $10^{5} \mathrm{~W} / \mathrm{cm}^{2}$ [33]. The laser beam opens $10-30$ subcapsular small follicles per ovary. The Nd:YAG laser is equipped with a sterile quartz glass fibre of $0.6-\mathrm{mm}$ core diameter, the power ranges between 30 and $60 \mathrm{~W}$. The focussed laser beam is used at a distance of $5-10 \mathrm{~mm}$ from the ovary [23]. This laser type coagulates tissue without vaporisation at low powers in a non-contact mode. Penetration depth depends on the applied energy and application time. The argon laser allows good vaporisation and coagulation effects [47]. When an argon laser technique is used, the power setting is $12-14 \mathrm{~W}$ in continuous mode using a disposable sapphire tip connected to a $600-\mathrm{mm}$ flexible fibre [38]. Ten to 40 holes are drilled.

Benefit of different laparoscopic ovarian drilling techniques

Today, there is no evidence that any one of the laparoscopic techniques should yield superior results. The studies are rather poor. Keckstein et al. [20] have treated 19 patients with the $\mathrm{CO}_{2}$ laser and 11 patients with the Nd:YAG laser system in a non-randomised study. In a follow-up between 18 months and 30 months, eight pregnancies in the $\mathrm{CO}_{2}$ laser group and three pregnancies after drilling with the Nd:YAG laser have been achieved (44\% vs. $27 \%)$.

Takeuchi et al. [40] compared ovarian drilling with a harmonic scalpel laser and a Nd:YAG laser in 17 patients per group. The endocrine profile after surgery was similar, the ovulation rate was $94 \%$ in both groups and the pregnancy rate within a follow-up of 2 years was $77 \%$ and $60 \%$, respectively, without significant differences.

\section{Additional operative procedures}

Ovaries are cooled during the procedure by rinsing with Ringer's lactate [26], saline solution [30, 28], Hartmann's solution [38] or $10 \%$ dextran solution with $500 \mathrm{ml}$ artificial ascites [33]. Some groups use hyaluronic acid gel as an adhesion barrier at the end of the procedure [45]. Greenblatt and Casper have used Interceed to wrap one ovary in a comparative study [26].

\section{Transvaginal approach}

In standard laparoscopical procedure, a $\mathrm{CO}_{2}$ pneumoperitoneum is used. Fernandez et al. [37] have introduced a transvaginal approach by transvaginal hydrolaparoscopy. The pouch of Douglas was punctured with a Veress needle and $300 \mathrm{ml}$ of normal saline solution was instilled through the posterior vaginal fornix. Vaporisation was achieved by a bipolar electrosurgical probe called Versapoint. The conductivity of normal saline solution was used to advance the two electrodes along the axis of the device. The high energy level of 110-130 W produced steam at the distal electrode end and, thereby, vaporised the ovarian tissue. 


\section{Pathomechanism}

Although the technique has been widely used in the last two decades, the underlying pathomechanism is yet unclear, but it should cause similar effects as wedge resection. Ovarian drilling might destroy tissue of the ovarian cortex and stroma and drain small, androgenic follicles, thus, leading to a decrease of intraovarian androgen levels and androgen production. Consecutively, the peripheral conversion of androgens to oestrogens should be lowered, resulting in a correction of LH hypersecretion on the pituitary level [48]. Furthermore, lower androgen shall convert the intraovarian androgenic milieu to an oestrogenic one [49]. This mechanism shall diminish the atresia of chronically hyperandrogenic small follicles and restore normal follicular recruitment [50]. Drainage of small follicles with a hyperandrogenic milieu might be the most important effect [29]. This hypothesis is underlined by a study of Ferraretti et al. [51], who showed comparable endocrine effects by simply aspirating small follicles by transvaginal ovarian puncture without destroying ovarian tissue. According to the proposed pathomechanism, insulin resistance and hyperinsulinaemia should not be influenced by the surgical concept.

Indeed, these effects on gonadotrophin production can be confirmed and are similar to ovarian wedge resection. The LH and FSH levels increase significantly during the first 2 days after drilling [30], followed by a persistent decline of LH [26, 21, 52-55]. In contrast to FSH, LH levels remain low for many years $[21,56]$. Low LH levels were confirmed over a period of more than 3 years [55]. However, secondary increasing FSH levels are discussed controversely. Amer et al. [55] did not find significant FSH variations after a 3-year follow-up. A normalised inhibin pulsatility further indicates normal intraovarian paracrine signalling [57].

Androgen levels and the free androgen index (FAI) are persistently suppressed, partially due to a significant increase of SHBG, but mainly as a result of persistently lowered LH levels. Young PCOS patients show lower androgen levels within 3 months after drilling and a significant increase of ovarian blood flow, but no effects on leptin levels [58]. Ovarian drilling does not affect adrenal steroidogenesis, as demonstrated by adrenocorticotropic hormone $(\mathrm{ACTH})$ tests in 14 voluntary patients [59].

At least $30 \%$ of PCOS patients show metabolic disorders, such as hyperinsulinemia and insulin resistance. Ovarian drilling displays some beneficial effects on glucose and insulin responses in an oral glucose challenge test [59], although these findings could not be confirmed by others [60]. Hyperglycaemic clamping did not show any improvement in insulin sensitivity after ovarian drilling [61]. Today, there is no evidence that ovarian drilling might positively influence insulin resistance.

Ovarian drilling significantly reduces the ovarian volume $[55,62]$. Furthermore, ovarian vascularisation is increased, with a significantly higher pulsatility index and resistance index [63]. Data concerning the number of drilling holes needed to achieve positive effects on hormonal profiles, ovulation rate and pregnancy is limited. In a rather small prospective, randomised study, Balen and Jacobs [28] performed unilateral LOD in four patients and bilateral LOD in six patients. They could not demonstrate the occurrence of pregnancies, but patients after unilateral LOD ovulated from both sides and they discussed that correction of the disturbed ovarianpituitary feedback might be the most important effect of LOD.

\section{Results}

\section{Ovulation and pregnancy rate}

Reports on ovarian drilling reveal excellent results. Even clomiphene-resistant patients show a high rate of spontaneous ovulations after the laparoscopic procedure [48]. The original work by Gjönnaess [16] describes an ovulation rate of $92 \%$ and a pregnancy rate of $80 \%$. Six months after drilling, standard ovulation rates are between $63 \%$ and $81 \%$ [31, 32, 43]. Ovulation seems to be independent of the drilling technique [23, 24]. Results of the studies are given in Table 1.

In 57 patients, Cleeman et al. [64] have shown that the average time to pregnancy was 135 days, leading to an overall pregnancy rate of $61 \%$. Therefore, these authors consider laparoscopic ovarian drilling as first-line treatment in anovulatory PCOS patients.

However, there are only few prospective randomised controlled trials. Randomised studies compared hormonal stimulation with LOD or other treatment options with LOD, such as metformin, unilateral and bilateral diathermy or different laser systems (Table 2). Only randomised controlled trials will be introduced in more detail in this review and discussed in special sections.

\section{Long-term follow-up}

The duration of drilling effects on cycle length and ovulation rate is still under debate. Whereas some authors describe only transient beneficial results of approximately 1 year $[16,20,25]$, the positive effects might last much longer, for a number of years $[56,65$, 38].

A long-term follow-up by Naether et al. [65] reported a number of 211 pregnancies, including 50\% spontaneous pregnancies. Another study compared a follow-up of 8 years after ovarian drilling by thermocoagulation in 116 patients, with 34 patients after hormonal treatment [38]. About 31 patients after drilling and seven of the control group were lost to follow-up, the others were studied between 3 and 9 years. At the end of the observation time, patients after drilling showed ovulatory cycles in $55 \%$ compared to $8 \%$ before surgery, 


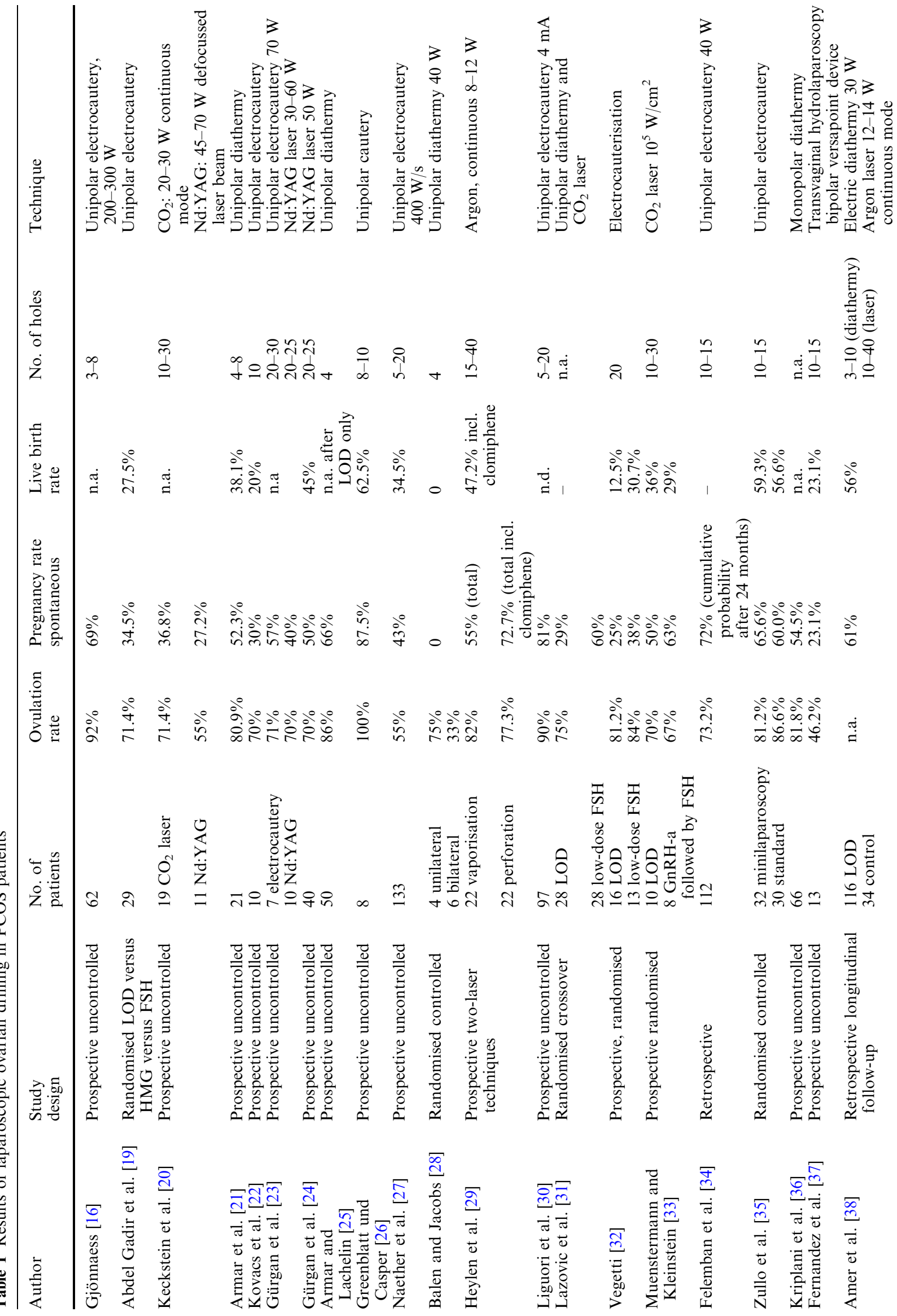




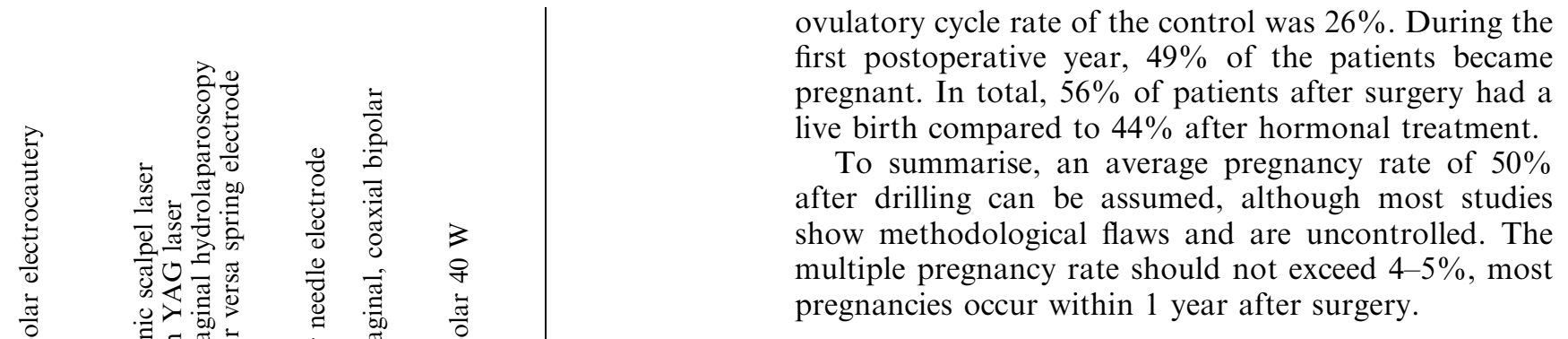

ovulatory cycle rate of the control was $26 \%$. During the first postoperative year, $49 \%$ of the patients became pregnant. In total, $56 \%$ of patients after surgery had a ve birth compared to $44 \%$ after hormonal treatment.

of $50 \%$ show methodological flaws and are uncontrolled. The pregnancies occur within 1 year after surgery.

\section{Comparison to hormonal stimulation}

The most widely used standard treatment in infertile PCOS patients is low-dose gonadotrophin stimulation, in particular with FSH. These stimulation protocols were introduced in the early nineties and have a low hyperstimulation rate with monofollicular cycles in at least $50 \%$ of stimulation cycles [66]. Nevertheless, these protocols yield a higher multiple pregnancy rate compared to ovarian drilling [67]. On the contrary, a certain disadvantage of ovarian drilling is the need of an invasive surgical procedure and a $20 \%$ risk of de novo adhesion formation [30]. Vegetti et al. [32] randomised 16 patients to LOD and 13 patients to receive low-dose FSH treatment. The spontaneous ovulation rate after LOD was $81.2 \%$ and there was a $25 \%$ pregnancy rate per patient. The ovulation rate after FSH treatment was $84 \%$, unifollicular development occurred in $63 \%$ of patients and a pregnancy rate of $38 \%$ per patient was achieved. This data were reported as abstract only. Abdel Gadir et al. [19] compared electrocautery with low-dose HMG or FSH stimulation and found that electrocautery was equally effective as $\mathrm{HMG}$ or $\mathrm{FSH}$ treatment after six cycles. Lazovic et al. [31] chose a randomised crossover design in 56 patients of LOD with a $\mathrm{CO}_{2}$ laser versus six cycles of $\mathrm{HMG}$ or $\mathrm{FSH}$. The number of drilled holes was not stated. The data were available as abstract only. In a follow-up of 6 months after drilling or three cycles of gonadotrophins, there was no difference concerning rates of ovulation and pregnancy.

Farquhar et al. [39] have published a controlled randomised trial of 28 patients after electrocautery and 19 patients after three cycles of low-dose HMG/FSH. Initially, one patient in the electrocautery group and two patients of the hormonal treatment group had been excluded. The pregnancy rate did not show a significant difference. Interestingly, 19 patients underwent both treatments after the end of the follow-up. About 17 patients returned a questionnaire and 15 of them preferred laparoscopic ovarian diathermy instead of ovarian stimulation.

In a multicentre study comparing low-dose FSH stimulation and electrocautery in a total of 168 PCOS patients, Bayram et al. [43] reported a $67 \%$ cumulative pregnancy rate after stimulation, compared to only $34 \%$ after electrocautery. In the 83 patients of the electrocautery group, 45 patients had persistent anovulatory 
Table 2 Randomised controlled trials in laparoscopic ovarian drilling (no abstracts)

\begin{tabular}{|c|c|c|c|c|}
\hline Author & $\begin{array}{l}\text { Trial } \\
\text { design }\end{array}$ & $\begin{array}{l}\text { No. of } \\
\text { patients }\end{array}$ & $\begin{array}{l}\text { Ovulation } \\
\text { rate }\end{array}$ & $\begin{array}{l}\text { Pregnancy } \\
\text { rate }\end{array}$ \\
\hline \multirow[t]{3}{*}{ Abdel Gadir [19] } & LOD & 29 & $71.4 \%$ & $52.1 \%$ \\
\hline & HMG & 30 & $70.6 \%$ & $38.3 \%$ \\
\hline & FSH & 28 & $66.7 \%$ & \\
\hline \multirow{2}{*}{ Balen and Jacobs [28] } & Unilateral & 4 & $75 \%$ & $0 \%$ \\
\hline & Bilateral LOD & 6 & $33 \%$ & $0 \%$ \\
\hline \multirow[t]{2}{*}{ Farquhar et al. [39] } & LOD & 28 & $54 \%$ & $28.5 \%$ \\
\hline & Three cycles HMG/FSH & 19 & $81 \%$ per cycle & $21.2 \%$ \\
\hline \multirow{2}{*}{$\begin{array}{l}\text { Münstermann and } \\
\text { Kleinstein [33] }\end{array}$} & LOD & 10 & $70 \%$ & $50 \%$ \\
\hline & $\begin{array}{l}6 \text { months GnRH analogues } \\
\text { followed by three cycles } \\
\text { low-dose FSH }\end{array}$ & 8 & 67\% (FSH stimulat.) & $63 \%$ \\
\hline \multirow[t]{2}{*}{ Takeuchi et al. [40] } & Harmonic scalpel laser & 17 & $94 \%$ & $77 \%$ \\
\hline & Nd:YAG laser & 17 & $94 \%$ & $60 \%$ \\
\hline \multirow[t]{2}{*}{ Bayram et al. [43] } & Electrocautery & 83 & $70 \%$ & $34 \%$ \\
\hline & Six cycles FSH & 85 & n.a. & $67 \%$ \\
\hline \multirow[t]{2}{*}{ Palomba et al. [45] } & Metformin & 54 & $54.8 \%$ & $18.6 \%$ \\
\hline & LOD & 55 & $53.3 \%$ per cycle & $13.4 \%$ per cycle \\
\hline
\end{tabular}

cycles and received clomiphene during follow-up. However, when hormonal stimulation with clomiphene or FSH was used during the follow-up additionally, the cumulative pregnancy rate after 12 months was exactly the same $(67 \%)$, with a lower number of multiple pregnancies after electrocautery compared to FSH stimulation only.

To date, there is no data available which could give evidence that operative techniques are superior to hormonal stimulation. A second Cochrane analysis on this topic showed no difference between ovarian drilling over a 12-month follow-up period and a course of 3-6 hormonal stimulation cycles in a low-dose FSH protocol [68], including four studies with direct comparison of ovarian drilling and low-dose FSH. No studies are published showing a possible benefit of ovarian drilling after a longer follow-up. Bearing in mind that the majority of pregnancies after drilling will occur during the first year, this seems to be rather unlikely.

\section{Comparison to metformin}

There is no data available on the possible beneficial effects of combined ovarian drilling and metformin [69]. In a recent prospective parallel randomised double-blind placebo-controlled trial, Palomba et al. [45] compared metformin treatment for a maximum of 6 months, together with a 6 month follow-up after LOD. No difference in the bleeding pattern was observed. At the end of the study, the total ovulation rate was not different. The pregnancy rate was significantly higher in the metformin group $(18.6 \%$ vs. $13.4 \%)$, as well as with a significantly lower abortion rate. In contrast, Malkawi et al. [42] could not demonstrate any significant difference between the treatment with metformin $2 \times 850 \mathrm{mg}$ daily and laparoscopic ovarian drilling concerning ovulation rate $(70.7 \%$ vs. $83.5 \%)$ and pregnancy rate $(64.1 \%$ vs. $59.8 \%)$.

\section{Combined effects of laparoscopic ovarian drilling and hormonal stimulation}

Ovarian reaction to FSH stimulation in in vitro fertilisation (IVF) cycles might improve after ovarian drilling. Ovarian drilling followed by IVF should lead to a higher number of oocytes retrieved and a significantly improved embryonic development [51]. However, these results must be interpreted with caution, since the authors have used a significantly higher FSH dosage in IVF cycles after ovarian drilling.

Farhi et al. [62] compared the results of HMG stimulation before and after LOD. If no spontaneous pregnancy occurred within 6 months after LOD HMG or FSH, stimulation was initiated again. The ovulation rate per cycle increased significantly from $48 \%$ to $71 \%$ after HMG and from $50 \%$ to $71 \%$ after FSH treatment. The LOD before hormonal stimulation should reduce the rate of multiple follicular growth and, therefore, multiple pregnancies. However, ovarian down regulation for 6 months before low-dose FSH stimulation is equally effective in order to avoid multiple pregnancies [33]. In a prospective, randomised study, the authors used three FSH stimulation cycles after electrocautery or after 6 months of GnRH analogue ovarian suppression. In both groups, $30 \%$ of stimulated cycles were persistently anovulatory. The pregnancy rate of $36 \%$ was exactly the same. In a recent study by Bayram et al. [43], a quintuplet pregnancy with low-dose FSH after electrocautery has been described. However, it remains unclear whether a correct low-dose protocol was applied in this individual case.

\section{Consecutive indications for laparoscopic ovarian drilling}

Subgroups of patients who could have a primary advantage from ovarian drilling are yet not adequately 
defined. Low-dose FSH stimulation in poor responders might be more successful after ovarian drilling, although the pregnancy rate did not improve significantly [62]. On the contrary, patients with hyperstimulation, even in a low-dose protocol, might benefit from electrocautery, only without hormonal treatment, thus, avoiding multifollicular development. Some negative predictive factors for successful ovarian drilling were postulated by Amer et al. [70]: BMI $>35$, testosterone $>4.5 \mathrm{nmol} / 1$, FAI $>15$, infertility $>3$ years. In these groups, the indication for electrocautery should be made with caution.

\section{Risks of laparoscopic ovarian drilling}

The main risk besides the general risks of laparoscopic surgery is the formation of de novo adhesions. In an experimental study performed on rabbits, Keckstein et al. [71] could not demonstrate a high grade of adhesions. Adhesion rate was independent from the type of laser used, after Nd:YAG laser 1 of 19, argon laser 1 of 10 and $\mathrm{CO} 2$ laser 3 of 13. In humans, eight of eight patients showed ovarian adhesions, which were removed in a second-look laparoscopy [26]. Nevertheless, all patients experienced ovulatory cycles and seven patients conceived. Interestingly, there was no difference between ovaries wrapped with Interceed or without an adhesion barrier. In a very limited study in 17 patients, Gürgan et al. [23] described adhesions in six out of seven patients after electrocautery and in eight out of ten patients after $\mathrm{Nd}$ :YAG laser. However, a second-look laparoscopy is not mandatory. In studies by Gürgan et al. [23, 24], pregnancy rates in 19 patients with and 20 patients without second-look laparoscopy were not different after 6 months. Liguori et al. [30] performed 30 secondlook laparoscopies after 90 cases of ovarian drilling and found minimal to moderate adhesions in seven cases only. In a study by Felemban et al. [34], a rate of $27 \%$ postoperative adhesions was reported in a total of 17 patients. To summarise, the grade of adhesions after LOD varies substantially and is described as between $0 \%$ and $70 \%$ [48]. Today, there is no sufficient evidence that the laparoscopic technique influences the grade of adhesion formation [68].

Although general risks are rare, one case of pelvic infection following LOD has been reported [72]. In transvaginal hydrolaparoscopy, Casa et al. [41] have described bleeding complications in one case requiring conversion to classical laparoscopy.

\section{Future development of laparoscopic ovarian drilling}

Currently, laparoscopic ovarian drilling is performed by standard laparoscopic techniques using general anaesthesia. Zullo et al. [35] compared classical laparoscopic ovarian drilling with ovarian drilling by mini-laparoscopy under local anaesthesia, and found no differences concerning endocrine postoperative parameters, ovulation rates and pregnancy rates. Classic laparoscopy was complicated by a greater need of postoperative analgetic treatment and longer hospitalisation.

Furthermore, a new transvaginal approach by hydrolaparoscopy could facilitate the procedure. Transvaginal hydrolaparoscopy requires a high training level. The technique has already been performed in 13 clomiphene-resistant PCOS patients with a coaxial bipolar electrode [37]. Six of 13 patients achieved normal ovulatory cycles within 6 months. Six pregnancies were reported; three spontaneous pregnancies, two pregnancies after hormonal stimulation and consecutive intrauterine insemination and one IVF pregnancy. The same technique was used by Casa et al. [41], giving a $66 \%$ ovulation rate and a cumulative pregnancy rate of $76 \%$ after 6 months, although 5 of 13 pregnancies needed additional hormonal stimulation [41]. Ramzy et al. [73] treated 52 patients by ultrasound-guided transvaginal injection of warm saline $\left(75^{\circ} \mathrm{C}\right)$ transvaginally into the ovarian stroma. Ovulation could be achieved in $73.1 \%$ of patients, resulting in a pregnancy rate of $26.9 \%$.

\section{Conclusion}

Laparoscopic ovarian drilling is an interesting alternative approach to treat anovulatory polycystic ovary syndrome (PCOS) patients, although its indications are yet not well defined. The results are not superior to direct hormonal stimulation, but yield a lower multiple pregnancy rate and avoid the risk of ovarian hyperstimulation. Furthermore, laparoscopic ovarian drilling (LOD) normalises the hormonal environment, provides long-term effects and might improve the ovarian reaction to hormonal treatment. The need of a surgical approach and the formation of de novo adhesions is a major disadvantage of the method. In hyperinsulinemic patients, metformin treatment seems to offer higher pregnancy rates. Therefore, ovarian drilling must not be considered as the treatment of first choice. Patients with poor response to hormonal stimulation or disagreement with repeated multifollicular reaction to gonadotrophin stimulation might benefit from the surgical approach.

\section{References}

1. The Rotterdam ESHRE/ASRM-Sponsored PCOS consensus workshop group (2004) Revised 2003 consensus on diagnostic criteria and long-term health risks related to polycystic ovary syndrome (PCOS). Hum Reprod 19:41-47

2. Yen SSC (1980) The polycystic ovary syndrome. Clin Endocrinol 12:177-207

3. Dunaif A, Segal KR, Futterweit W, Dobrjansky A (1989) Profound peripheral insulin resistance, independent of obesity, in polycystic ovary syndrome. Diabetes 38:1165-1174

4. Moghetti P, Tosi F, Castello R, Magnani CM, Negri C, Brun E, Furlani L, Caputo M, Muggeo M (1996) The insulin resistance in women with hyperandrogenism is partially reversed by antiandrogen treatment: evidence that androgens impair insulin action in women. J Clin Endocrinol Metab 81:952-960 
5. Nestler JE, Jakubowicz DJ, Evans WS, Pasquali R (1998) Effects of metformin on spontaneous and clomiphene-induced ovulation in the polycystic ovary syndrome. N Engl $\mathbf{J}$ Med 338:1876-1880

6. Nestler JE, Powers LP, Matt DW, Steingold KA, Plymate SR, Rittmaster RS, Clore JN, Blackard WG (1991) A direct effect of hyperinsulinemia on serum sex hormone-binding globulin levels in obese women with the polycystic ovary syndrome. J Clin Endocrinol Metab 72:83-89

7. Velazquez E, Acosta A, Mendoza SG (1997) Menstrual cyclicity after metformin therapy in polycystic ovary syndrome. Obstet Gynecol 90:392-395

8. Velazquez EM, Mendoza S, Hamer T, Sosa F, Glueck CJ (1994) Metformin therapy in polycystic ovary syndrome reduces hyperinsulinemia, insulin resistance, hyperandrogenemia, and systolic blood pressure, while facilitating normal menses and pregnancy. Metabolism 43:647-654

9. Stewart PM, Shackleton CH, Beastall GH, Edwards CR (1990) 5 alpha-reductase activity in polycystic ovary syndrome. Lancet 335:431-433

10. Rosenfield RL, Barnes RB, Cara JF, Lucky AW (1990) Dysregulation of cytochrome $\mathrm{P} 450 \mathrm{c} 17$ alpha as the cause of polycystic ovarian syndrome. Fertil Steril 53:785-791

11. Stein IF, Cohen MR (1935) Surgical treatment of bilateral polycystic ovaries. Am J Obstet Gynecol 38:465-473

12. Adashi EY, Rock JA, Guzick D, Wentz AC, Jones GS, Jones HW Jr (1981) Fertility following bilateral ovarian wedge resection: a critical analysis of 90 consecutive cases of the polycystic ovary syndrome. Fertil Steril 36:30-35

13. Buttram VC Jr, Vaquero C (1975) Post-ovarian wedge resection adhesive disease. Fertil Steril 26:874-876

14. Eddy CA, Asch RH, Balmaceda JP (1980) Pelvic adhesions following microsurgical and macrosurgical wedge resection of the ovaries. Fertil Steril 33:557-561

15. Lunde O, Djoseland O, Grottum P (2001) Polycystic ovarian syndrome: a follow-up study on fertility and menstrual pattern in 149 patients $15-25$ years after ovarian wedge resection. Hum Reprod 16:1479-1485

16. Gjönnaess H (1984) Polycystic ovarian syndrome treated by ovarian electrocautery through the laparoscope. Fertil Steril 49:956-960

17. Daniell JF, Miller W (1989) Polycystic ovaries treated by laparoscopic laser vaporization. Fertil Steril 51:232-236

18. Keckstein J, Finger A, Steiner R (1988) Laser application in contact and noncontact procedures: sapphire tips in comparison to "bare-fiber;" argon laser in comparison to Nd:YAG laser. Laser Med Surg 4:158-162

19. Abdel Gadir A, Mowafi R, Alnaser H, Alrashid A, Alonezi O, Shaw R (1990) Ovarian electrocautery versus human menopausal gonadotrophins and pure follicle stimulating hormone therapy in the treatment of patients with polycystic ovarian disease. Clin Endocrinol 33:585-592

20. Keckstein G, Rossmanith W, Spatzier K, Schneider V, Borschers K, Steiner R (1990) The effect of laparoscopic treatment of polycystic ovarian disease by $\mathrm{CO}_{2}$ laser or Nd:YAG laser. Surg Endosc 4:103-107

21. Armar N, McGarrigle H, Honour J, Holownia P, Jacobs H, Lachelin G (1990) Laparoscopic ovarian diathermy in the management of anovulatory infertility in women with polycystic ovaries: endocrine changes and clinical outcomes. Fertil Steril 53:45-49

22. Kovacs G, Buckler H, Bangah M, Outch K, Burger H, Healy D, Baker G, Phillips S (1991) Treatment of anovulation due to polycystic ovarian syndrome by laparoscopic ovarian electrocautery. Br J Obstet Gynaecol 98:30-35

23. Gürgan T, Kisnisci H, Yarali H, Develioglu O, Zeyneloglu H, Aksu T (1991) Evaluation of adhesion formation after laparoscopic treatment of polycystic ovarian disease. Fertil Steril $56: 1176-1178$

24. Gürgan T, Urman B, Aksu T, Yarali H, Develioglu O, Kisnisci H (1992) The effect of short-interval laparoscopic lysis of adhesions on pregnancy rates following Nd-YAG laser photocoagulation of polycystic ovaries. Obstet Gynecol 80:45-47

25. Armar NA, Lachelin GC (1993) Laparoscopic ovarian diathermy: an effective treatment for anti-oestrogen resistant anovulatory infertility in women with the polycystic ovary syndrome. Br J Obstet Gynaecol 100:161-164

26. Greenblatt E, Casper R (1993) Adhesion formation after laparoscopic ovarian cautery for polycystic ovarian syndrome: lack of correlation with pregnancy rate. Fertil Steril 60:766-770

27. Naether OG, Fischer R, Weise HC, Geiger-Kotzler L, Delfs T, Rudolf K (1993) Laparoscopic electrocoagulation of the ovarian surface in infertile patients with polycystic ovarian disease. Fertil Steril 60:88-94

28. Balen A, Jacobs HS (1994) A prospective study comparing unilateral and bilateral laparoscopic ovarian diathermy in women with the polycystic ovary syndrome. Fertil Steril 62:921-925

29. Heylen S, Puttemans P, Brosens I (1994) Polycystic ovarian disease treated by laparoscopic argon laser capsule drilling: comparison of vaporization versus perforation technique. Hum Reprod 9:1038-1042

30. Liguori G, Tolino A, Moccia G, Scognamiglio G, Nappi C (1996) Laparoscopic ovarian treatment in infertile patients with polycystic ovarian syndrome (PCOS): endocrine changes and clinical outcome. Gynecol Endocrinol 10:257-264

31. Lazovic G, Milacic D, Terzic M, Spremovic S, Mitijasevic S (1998) Medicaments or surgical therapy of PCOS. Fertil Steril 70:S472 (abstract band IFFS 98)

32. Vegetti W, Ragni G, Baroni E, Testa G, Marsico, S, Riccaboni A, Crosignani PG (1998) Laparoscopic ovarian drilling versus low-dose pure FSH in anovulatory clomiphene-resistant patients with polycystic ovarian syndrome: randomized prospective study. Hum Reprod 13:120 (abstract only)

33. Muenstermann U, Kleinstein J (2000) Long-term GnRH analogue treatment is equivalent to laparoscopic laser diathermy in polycystic ovarian syndrome patients with severe ovarian dysfunction. Hum Reprod 15:2526-2530

34. Felemban A, Tan SL, Tulandi T (2000) Laparoscopic treatment of polycystic ovaries with insulated needle cautery: a reappraisal. Fertil Steril 73:266-269

35. Zullo F, Pellicano M, Zupi E, Guida M, Mastrantonio P, Nappi C (2000) Minilaparoscopic ovarian drilling under local anaesthesia in patients with polycystic ovary syndrome. Fertil Steril 74:376-379

36. Kriplani A, Manchanda R, Agarwal N, Nayar B (2001) Laparoscopic ovarian drilling in clomiphene citrate-resistant women with polycystic ovary syndrome. J Am Assoc Gynecol Laparose 8:511-518

37. Fernandez H, Alby JD, Gervaise A, de Tayrac R, Frydman R (2001) Operative transvaginal hydrolaparoscopy for treatment of polycystic ovary syndrome: a new minimally invasive surgery. Fertil Steril 75:607-611

38. Amer SA, Gopalan V, Li TC, Ledger WL, Cooke ID (2002) Long term follow-up of patients with polycystic ovarian syndrome after laparoscopic ovarian drilling: clinical outcome. Hum Reprod 17:2035-2042

39. Farquhar CM, Williamson K, Gudex G, Johnson NP, Garland J, Sadler L (2002) A randomized controlled trial of laparoscopic ovarian diathermy versus gonadotropin therapy for women with clomiphene citrate-resistant polycystic ovary syndrome. Fertil Steril 78:404-411

40. Takeuchi S, Futamura N, Takubo S, Noda N, Minoura H, Toyoda N (2002) Polycystic ovary syndrome treated with laparoscopic ovarian drilling with a harmonic scalpel. A prospective, randomized study. J Reprod Med 47:816-820

41. Casa A, Sesti F, Marziali M, Gulemi L, Piccione E (2003) Transvaginal hydrolaparoscopic ovarian drilling using bipolar electrosurgery to treat anovulatory women with polycystic ovary syndrome. J Am Assoc Gynecol Laparosc 10:219-222

42. Malkawi HY, Qublan HS, Hamaideh AH (2003) Medical vs. surgical treatment for clomiphene citrate-resistant women with polycystic ovary syndrome. J Obstet Gynecol 23:289-293 
43. Bayram N, Van Wely M, Kaaijk EM, Bossuyt P, Van der Veen F (2004) Using an electrocautery strategy or recombinant follicle stimulating hormone to induce ovulation in polycystic ovary syndrome: randomised controlled trial. BMJ 328:192196

44. Fernandez H, Watrelot A, Alby JD, Kadoch J, Gervaise A, deTayrac R, Frydman R (2004) Fertility after ovarian drilling by transvaginal fertiloscopy for treatment of polycystic ovary syndrome. J Am Assoc Gynecol Laparosc 11:374-378

45. Palomba S, Orio F, Nardo LG, Falbo A, Russo T, Corea D, Doldo P, Lombardi G, Tolino A, Colao A, Zullo F (2004) Metformin administration versus laparoscopic ovarian diathermy in clomiphene citrate-resistant women with polycystic ovary syndrome: a prospective parallel randomized doubleblind placebo-controlled trial. J Clin Endocrinol Metab 89:4801-4809

46. Li TC, Saravelos H, Chow MS, Chisabingo R, Cooke ID (1998) Factors affecting the outcome of laparoscopic ovarian drilling for polycystic ovarian syndrome in women with anovulatory infertility. Br J Obstet Gynaecol 105:338-344

47. Keckstein J, Tuttlies F, Steiner R (1989) Lasereffekt am Ovar: $\mathrm{CO}_{2}$ versus Nd:YAG versus argon. In: Proceedings of the 4th Jahrestagung der Deutschen Gesellschaft für Lasermedizin, Ulm, Germany, September 1989, pp 84-88

48. Gomel V, Yarali H (2004) Surgical treatment of polycystic ovary syndrome associated with infertility. Reprod Biomed Online 9:35-42

49. Aakvaag A (1985) Hormonal response to electrocautery of the ovary in patients with polycystic ovarian disease. $\mathrm{Br} \mathbf{J}$ Obstet Gynaecol 92:1258-1264

50. Balen A, Tan SL, Jacobs H (1993) Hypersecretion of luteinising hormone. A significant cause of infertility and miscarriage. $\mathrm{Br}$ J Obstet Gynaecol 100:1082-1089

51. Ferraretti AP, Gianaroli L, Magli MC, Iammarrone E, Feliciani E, Fortini D (2001) Transvaginal ovarian drilling: a new surgical treatment for improving the clinical outcome of assisted reproductive technologies in patients with polycystic ovary syndrome. Fertil Steril 76:812-816

52. Sakata M, Tasaka K, Kurachi H (1990) Changes of bioactive luteinizing hormone after laparoscopic ovarian cautery in patients with polycystic ovarian syndrome. Fertil Steril 53:10-13

53. Rossmanith W, Keckstein J, Spatzier K, Lauritzen C (1991) The impact of ovarian laser surgery on gonadotrophin secretion in women with polycystic ovarian disease. Clin Endocrinol (Oxford) 34:23-30

54. Alborzi S, Khodaee R, Parsanejad ME (2001) Ovarian size and response to laparoscopic ovarian electro-cauterization in polycystic ovarian disease. Int J Gynaecol Obstet 74:269-274

55. Amer SA, Banu Z, Li TC, Cooke ID (2002) Long-term followup of patients with polycystic ovary syndrome after laparoscopic ovarian drilling: endocrine and ultrasonographic outcomes. Hum Reprod 17:2851-2857

56. Gjönnaess H (1998) Late endocrine effects of ovarian electrocautery in women with polycystic ovary syndrome. Fertil Steril 69:697-701

57. Lockwood GM, Muttukrishna S, Groome NP, Ledger WL (1998) Midfollicular phase pulses of inhibin B are absent in polycystic ovarian syndrome and are initiated by successful laparoscopic ovarian diathermy: a possible mechanism regulating emergence of the dominant follicle. J Clin Endocrinol Metab 83:1730-1735
58. Wu MH, Huang MF, Tsai SJ, Pan HA, Cheng YC, Lin YS (2004) Effects of laparoscopic ovarian drilling on young adult women with polycystic ovarian syndrome. J Am Assoc Gynecol Laparose 11:184-190

59. Saleh A, Morris D, Tan SL, Tulandi T (2001) Effects of laparoscopic ovarian drilling on adrenal steroids in polycystic ovary syndrome patients with and without hyperinsulinemia. Fertil Steril 75:501-504

60. Tulandi T, Saleh A, Morris D, Jacobs HS, Payne NN, Tan SL (2000) Effects of laparoscopic ovarian drilling on serum vascular endothelial growth factor and on insulin responses to the oral glucose tolerance test in women with polycystic ovary syndrome. Fertil Steril 74:585-588

61. Tiitinen A, Tenhunen A, Seppala M (1993) Ovarian electrocauterization causes LH-regulated but not insulin-regulated endocrine changes. Clin Endocrinol (Oxford) 39:181-184

62. Farhi J, Soule S, Jacobs HS (1995) Effect of laparoscopic ovarian electrocautery on ovarian response and outcome of treatment with gonadotropins in clomiphene citrate-resistant patients with polycystic ovary syndrome. Fertil Steril 64:930-935

63. Amin AF, Abd el-Aal DE, Darwish AM, Meki AR (2003) Evaluation of the impact of laparoscopic ovarian drilling on Doppler indices of ovarian stromal blood flow, serum vascular endothelial growth factor, and insulin-like growth factor-1 in women with polycystic ovary syndrome. Fertil Steril 79:938-941

64. Cleeman L, lauszus FF, Trolle B (2004) Laparoscopic ovarian drilling as first line of treatment in infertile women with polycystic ovary syndrome. Gynecol Endocrinol 18:138-143

65. Naether OG, Baukloh V, Fischer R, Kowalczyk T (1994) Long-term follow-up in 206 infertility patients with polycystic ovarian syndrome after laparoscopic electrocautery of the ovarian surface. Hum Reprod 9:2342-2349

66. Strowitzki T, Seehaus D, Korell M, Hepp H (1998) Low-dose FSH stimulation in polycystic ovary syndrome: comparison of 3 FSH preparations. Exp Clin Endocrinol Diabetes 106:435439

67. Farquhar C, Vandekerckhove P, Lilford R (2002) Laparoscopic "drilling" by diathermy or laser for ovulation induction in anovulatory polycystic ovary syndrome (Cochrane Review). In: The Cochrane library, issue 4. Update Software, Oxford

68. Farquhar C, Vandekerckhove P, Lilford R (2003) Laparoscopic "drilling" by diathermy or laser for ovulation induction in anovulatory polycystic ovary syndrome (Cochrane Review). In: The Cochrane library, issue 1, Update Software, Oxford

69. Pirwany I, Tulandi T (2003) Laparoscopic treatment of polycystic ovaries: is it time to relinquish the procedure? Fertil Steril 80:241-251

70. Amer SA, Li TC, Ledger WL (2004) Ovulation induction using laparoscopic ovarian drilling in women with polycystic ovarian syndrome: predictors of success. Hum Reprod 19:1719-1724

71. Keckstein J, Tuttlies F, Steiner R (1990) Laser therapy of polycystic ovary syndrome: in vivo study of adhesion and tissue reduction after application of $\mathrm{CO}_{2-}, \mathrm{Nd}$ :YAG- and argon laser radiation. Laser Med Surg 6:21-24

72. Deans A, Wayne C, Toplis P (1997) Pelvic infection: a complication of laparoscopic drilling. Gynaecol Endocrinol 6:301-303

73. Ramzy AM, Al-Inany H, Aboulfoutouh I, Sataar M, Idrees OA, Shehata MH (2001) Ultrasonographic guided ovarian stroma hydrocoagulation for ovarian stimulation in polycystic ovary syndrome. Acta Obstet Gynecol Scand 80:1046-1050 